\title{
Characteristics, Treatment and Outcome of Patients with Non-ST-Elevation Acute Coronary Syndromes and Multivessel Coronary Artery Disease: Observations from PURSUIT (Platelet Glycoprotein IIb/IIla in Unstable Angina: Receptor Suppression Using Integrelin Therapy)
}

\author{
Arno Breeman ${ }^{a}$ Nestor Mercado ${ }^{a}$ Mattie Lenzen ${ }^{a}$ \\ Marcel M.J . van den Brand ${ }^{a}$ Robert A. Harrington ${ }^{b}$ Robert M. Califf ${ }^{b}$ \\ Eric J . Topolc Maarten L. Simoons ${ }^{a}$ Eric Boersma ${ }^{a}$ \\ for the PURSUIT Investigators
}

aThorax Center, Erasmus University Medical Center, Rotterdam, The Netherlands; ' Duke Clinical Research Institute,

Durham, N.C., and ${ }^{\mathrm{C} C l e v e l a n d ~ C l i n i c ~ F o u n d a t i o n, ~ C l e v e l a n d, ~ O h i o, ~ U S A ~}$

\section{Key Words}

Multivessel disease - Medical treatment - Percutaneous coronary interventions $\cdot$ Coronary artery bypass grafting

\begin{abstract}
Background: The 6-month clinical outcome of patients with multivessel disease enrolled in PURSUIT (Platelet Glycoprotein Ilb/IIla in Unstable Angina: Receptor Suppression Using Integrilin Therapy) is described. Patients with complete angiography data were included; multivessel disease was stratified according to the treatment strategy applied early during hospitalization, i.e. medical treatment, percutaneous coronary intervention ( $\mathrm{PCl})$ (balloon), $\mathrm{PCl}$ (stent), or coronary artery bypass grafting (CABG). Methods: Patients were divided into three groups according to the treatment strategy applied during the first 30 days of enrolment. Patients who did not undergo a percutaneous or surgical coronary intervention were classified as medically treated. Patients who underwent a $\mathrm{PCl}$ (prior to a possible CABG) were sepa-
\end{abstract}

rated from those who underwent a CABG (prior to a possible $\mathrm{PCl}$ ). The $\mathrm{PCl}$ group was further subdivided: patients receiving $\geq 1$ coronary stents were separated from those in whom no stents were used. Results: The mortality rate at 30 days was $6.7,3.9,2.4$ and $4.8 \%$ for the medical treatment, $\mathrm{PCl}$ (balloon), $\mathrm{PCl}$ (stent) and CABG groups, respectively ( $p$ value $=0.002$ ). Differences as observed at 30 days were still present at 6-month followup with $11.1,5.8,5.5$ and $6.5 \%$ mortality event rates for the aforementioned groups ( $p$ value $=0.002$ ). The 30-day myocardial infarction (MI) rate according to the opinion of the Clinical Events Committee was lower among medically than non-medically treated patients, with the highest event rate observed in the CABG group (27.7\%). Approximately half of the MIs in the PCl and CABG subgroups occurred within $48 \mathrm{~h}$ after the procedure. Conclusions: The observed differences in clinical outcomes are explained by an imbalance in baseline characteristics and comorbid conditions between the analyzed groups of patients.

Copyright $\odot 2002$ S. Karger AG, Basel

\begin{tabular}{ll}
\hline KARGER & ○ 2002 S. Karger AG, Basel \\
Fax +4161306 12 34 & 0008-6312/02/0984-0195\$18.50/0 \\
E-Mail karger@karger.ch & Accessible online at: \\
www.karger.com & www.karger.com/crd
\end{tabular}

Dr. Eric Boersma
Thorax Center, Department of Cardiology
Erasmus University Medical Center, Room H-543
Dr Molewaterplein 40, NL-3015 GD Rotterdam (The Netherlands)
Tel. +31 10 4633909, Fax +31 10 4089484, E-Mail boersma@thch.azr.nl 


\section{Introduction}

Several clinical trials have been performed to evaluate whether patients with coronary artery disease benefit most from medical treatment only, percutaneous coronary intervention (PCI), or coronary bypass surgery (CABG) $[1,2]$. Other studies have specifically compared percutaneous transluminal coronary balloon angioplasty (PTCA) against CABG [3-9] and finally contemporary trials of coronary stenting and optimal adjunctive pharmacological therapy versus CABG have recently been reported [10-12]. However, most of these studies have predominantly included patients with chronic stable angina and few data are available on the characteristics and clinical outcome of patients with multivessel disease presenting with an acute coronary syndrome.

The Platelet Glycoprotein IIb/IIIa in Unstable Angina: Receptor Suppression Using Integrilin Therapy (PURSUIT) trial was a large-scale randomized clinical trial on the effects of eptifibatide versus placebo in patients with acute coronary syndromes without persistent ST elevation [13]. As the enrolment criteria were broad, PURSUIT encompasses a wide variety of patients, hospital settings and treatment policies, and therefore accurately reflects standard clinical practice.

The aim of this study was to describe the characteristics and short-term clinical outcome of patients with mul- tivessel coronary artery disease in the PURSUIT population according to the treatment strategy applied early during hospitalization.

\section{Materials and Methods}

\section{Patient Population}

The design and methods of the PURSUIT trial have been previously published [13]. In summary, patients were eligible if they presented within $24 \mathrm{~h}$ of an episode of ischemic chest pain (>10 min), and had either transient ST elevation $(>0.5 \mathrm{~mm})$, transient or persistent ST depression $(>0.5 \mathrm{~mm})$, T wave inversion $(>0.1 \mathrm{~mm})$, or elevation of the creatine kinase MB fraction (CK-MB) above the upper limit of normal (ULN). Patients with persistent (>30 min) ST elevation were excluded. Eligible patients were randomly assigned to treatment with eptifibatide or placebo. All other treatment decisions, including the use and timing of PCI or CABG were left at the discretion of the treating physician.

Coronary angiography was performed within 30 days of enrolment in 5,937 (63\%) of the 9,461 patients who participated in PURSUIT (fig. 1). Among patients with complete angiographic data, $3,067(58 \%)$ had a significant stenosis $(>50 \%$ diameter stenosis by visual inspection) in $\geq 2$ major native coronary arteries or in the left main stem. These patients were classified as having multivessel coronary artery disease and are the subjects of interest for the current analysis.

Classification According to Applied Treatment Strategy

Patients were divided into three groups according to the applied treatment strategy during the first 30 days of enrolment. Patients
Fig. 1. PURSUIT patient population flow chart stratified according to the number of diseased vessels and treatment strategy applied to patients with multivessel coronary disease. $\mathrm{VD}=$ vessel disease.

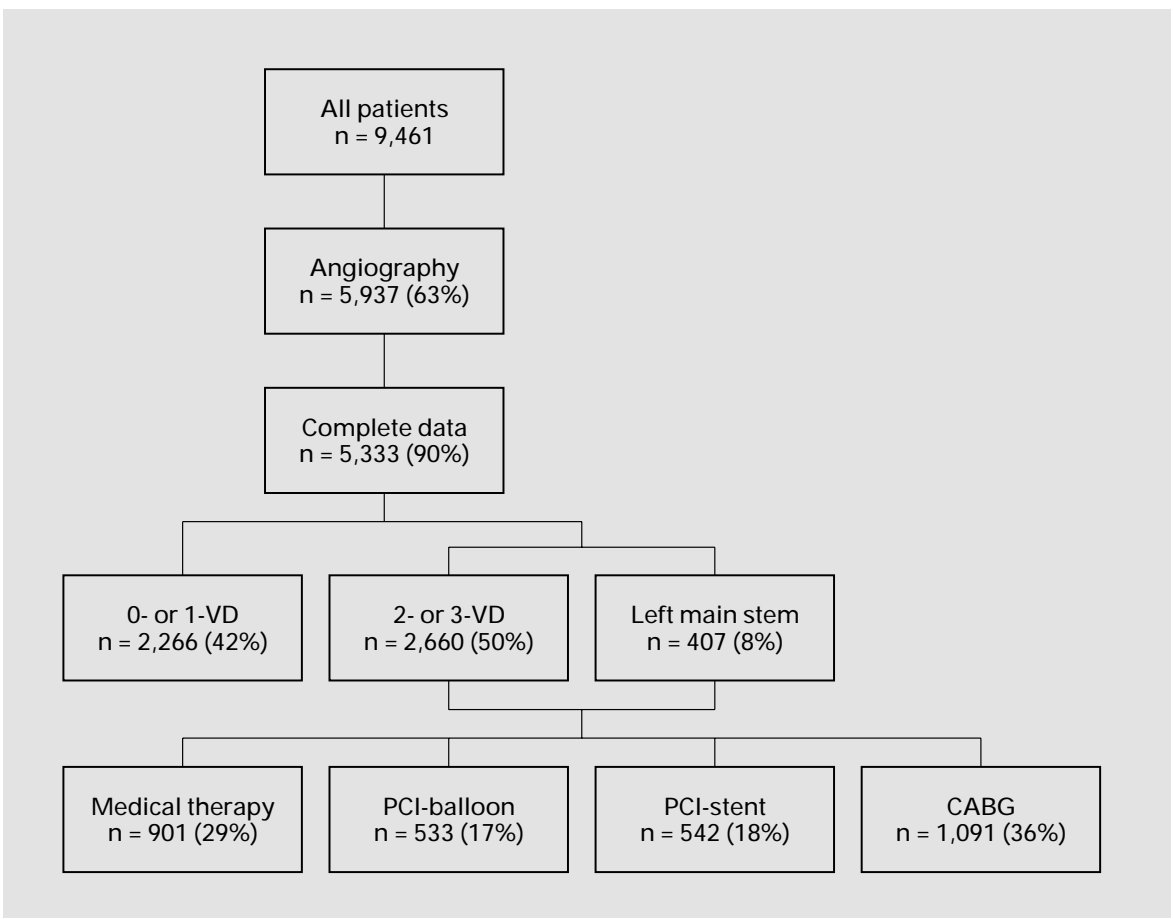


who did not undergo a percutaneous or surgical coronary intervention were classified as medically treated. Patients who underwent a PCI (prior to a possible CABG) were separated from those who underwent a CABG (prior to a possible PCI). The PCI group was further subdivided: patients receiving $\geq 1$ coronary stents were separated from those in whom no stents were used (fig. 1).

\section{Definition of Myocardial Infarction}

The primary endpoint of PURSUIT was a composite of death or nonfatal myocardial infarction (MI) at 30 days. A computerized algorithm was used to review the clinical events. If a possible event was identified, further documentation was collected and the case reviewed in detail and adjudicated by a central Clinical Events Committee (CEC). MI was diagnosed on the basis of new ST segment elevations, new Q waves, or new or repeated CK-MB elevations above the ULN. Following percutaneous or surgical intervention, the elevation of CK-MB level was required to be at least 3-5 times the ULN.

\section{Data Analysis}

The statistical analysis was performed using the SAS 8.0 software package (SAS Institute, Cary, N.C., USA). Continuous variables are presented as mean values \pm standard deviation and dichotomous variables as percentages. One-way analyses of variance (ANOVA) and $\chi^{2}$ tests were applied to evaluate differences in baseline characteristics, death, MI rates and rates of repeated coronary interventions (both at the 30-day and 6-month follow-up) between the different subgroups classified according to the applied treatment strategy. In case of a statistically significant difference in clinical events or repeated coronary interventions, which was specified at the conventional $\mathrm{p}<0.05$ level, repeated tests were performed to further evaluate the inter-subgroup differences. The Bonferroni method [14] was used to avoid spurious significant results after multiple testing, and the level of significance was lowered to $p<0.0167$ and $p<0.0083$ in case of 3 (balloon - stent - surgery) and 6 possible comparisons (medical treatment - balloon - stent - surgery), respectively.

Table 1. Clinical baseline characteristics

\begin{tabular}{|c|c|c|c|c|}
\hline & \multirow{2}{*}{$\begin{array}{l}\text { Medical } \\
(\mathrm{n}=901)\end{array}$} & \multicolumn{2}{|c|}{ PCI $(n=1,075)$} & \multirow{2}{*}{$\begin{array}{l}\text { CABG } \\
(\mathrm{n}=1,091)\end{array}$} \\
\hline & & $\begin{array}{l}\text { balloon } \\
(\mathrm{n}=533)\end{array}$ & $\begin{array}{l}\text { stent } \\
(\mathrm{n}=542)\end{array}$ & \\
\hline \multicolumn{5}{|l|}{ Demographics } \\
\hline Mean age $\pm S D$, years & $65 \pm 10$ & $63 \pm 11$ & $62 \pm 11$ & $64 \pm 10^{* * *}$ \\
\hline Male gender, $\%$ & 70 & 74 & 73 & 73 \\
\hline Caucasian, $\%$ & 86 & 89 & 91 & $90^{*}$ \\
\hline \multicolumn{5}{|l|}{ Medical history and risk factors } \\
\hline Hypertension, $\%$ & 62 & 60 & 61 & 57 \\
\hline Diabetes mellitus, \% & 30 & 26 & 23 & 27 \\
\hline Current smoker, $\%$ & 28 & 29 & 29 & 26 \\
\hline Hypercholesterolemia, \% & 50 & 46 & 53 & 47 \\
\hline Prior PCI, \% & 17 & 23 & 23 & $14^{* * *}$ \\
\hline Prior CABG, $\%$ & 36 & 24 & 29 & $9 * * *$ \\
\hline Prior MI, \% & 47 & 40 & 36 & $34 * * *$ \\
\hline Heart failure, $\%$ & 14 & 8 & 10 & $6^{* * *}$ \\
\hline Prior CVA, $\%$ & 7 & 4 & 5 & $3^{* *}$ \\
\hline Peripheral vessel disease, $\%$ & 13 & 8 & 9 & $9 * *$ \\
\hline \multicolumn{5}{|c|}{ Cardiac medication prior to admission } \\
\hline Aspirin, \% & 73 & 74 & 76 & 74 \\
\hline Beta-blocker, $\%$ & 48 & 50 & 49 & 49 \\
\hline Calcium antagonist, $\%$ & 39 & 34 & 36 & 36 \\
\hline Nitrates, $\%$ & 73 & 75 & 77 & 74 \\
\hline ACE inhibitors, $\%$ & 30 & 23 & 24 & $21 * * *$ \\
\hline \multicolumn{5}{|l|}{ Clinical presentation } \\
\hline CK-MB > 1 ULN, $\%$ & 52 & 52 & 44 & $48^{*}$ \\
\hline ST depression $>0.5 \mathrm{~mm}, \%$ & 52 & 47 & 52 & $58 * * *$ \\
\hline ST elevation $>0.5 \mathrm{~mm}, \%$ & 12 & 17 & 15 & $13^{*}$ \\
\hline T wave inversion $>0.5 \mathrm{~mm}, \%$ & 48 & 51 & 50 & 45 \\
\hline
\end{tabular}

$\mathrm{ACE}=$ Angiotensin converting enzyme; $\mathrm{CVA}=$ cerebrovascular accident; other abbreviations, as defined in the text. Statistical tests (integral comparison of 4 groups): ${ }^{*} p<0.05$; ** $\mathrm{p}<0.01 ; * * * \mathrm{p}<0.001$. 


\section{Results}

\section{Patient Characteristics}

During the first 30 days of randomization, a PCI was performed in 1,075 of 3,067 (35\%) patients, with stent placement in 542 cases (50\% of the PCI procedures), whereas 1,091 of 3,067 (36\%) patients underwent CABG. The remaining 901 (29\%) patients were medically treated (fig. 1). A significant difference was evident between the treatment subgroups with respect to age; medically treated and CABG patients were older than those undergoing PCI (table 1). There were also differences regarding history of prior cardiovascular events and interventions. Almost one quarter of the PCI patients had a previous PCI versus 17 and 14\% in the medical and surgical subgroups, respectively. A prior $\mathrm{CABG}$ was performed in $36 \%$ of medically treated patients, and this figure was only $9 \%$ in the CABG subgroup. A history of MI, heart failure, cerebrovascular accident, as well as peripheral vessel disease was more frequently observed in the medically versus non-medically treated patients. No important differences were observed in the use of cardiac medications except for the use of ACE inhibitors, which was more frequent in medically treated patients.

\section{Angiographic Findings}

Patients who underwent CABG had more severe coronary artery disease (52\% had 3-vessel and $21 \%$ left main disease), immediately followed by medically treated patients with a similar percentage of 3 -vessel disease (51\%) but less often, left main disease (11\%) (table 2). A total occlusion in any of the major native coronary arteries was more often present in medically than in non-medically treated patients. Medically and surgically treated patients not only had more severe, but also more diffuse coronary artery disease than PCI patients, as in $34 \%$ (CABG) to $40 \%$ (medically treated) of the patients, the culprit artery could not be identified; this percentage was only $8-10 \%$ in PCI patients. Left ventricular ejection fraction was lowest among medically treated patients. There were no apparent differences in coronary angiography results between PCI patients receiving stents and those that did not receive stents.

\section{Clinical Outcome}

The 30-day mortality rate was significantly higher among medically treated patients (6.7\%) than among those undergoing PCI either with $(2.4 \%)$ or without stent placement (3.9\%) (fig. 2). The observed difference in mortality rate $(\mathrm{p}$ value $=0.067)$ between medically treated and
Table 2. Coronary angiography results

\begin{tabular}{|c|c|c|c|c|}
\hline & Medical & PCI & & CABG \\
\hline & & balloon & stent & \\
\hline Vessel disease, $\%$ & & & & \\
\hline 2 & $38^{* *}$ & $62^{* *}$ & $61^{* *}$ & $28^{* * *}$ \\
\hline 3 & 51 & 32 & 30 & 52 \\
\hline LM & 11 & 6 & 9 & 21 \\
\hline Significant stenosis & $>50 \%) \mathrm{i}$ & & & \\
\hline RCA, $\%$ & 84 & 79 & 81 & $85^{* *}$ \\
\hline LAD, $\%$ & 88 & 77 & 82 & $91^{* * *}$ \\
\hline LCX, \% & 84 & 77 & 72 & $79 * * *$ \\
\hline $\mathrm{LM}, \%$ & 12 & 6 & 10 & $22 * * *$ \\
\hline Total occlusion (DS & $00 \%)$ in & & & \\
\hline RCA, \% & 48 & 33 & 33 & $33^{* * *}$ \\
\hline LAD, $\%$ & 35 & 24 & 26 & $20 * * *$ \\
\hline $\mathrm{LCX}, \%$ & 32 & 21 & 21 & $17^{* * *}$ \\
\hline Culprit artery, \% & & & & \\
\hline RCA & 14 & 27 & 25 & $16^{* * *}$ \\
\hline LAD & 21 & 25 & 29 & $29 * * *$ \\
\hline LCX & 14 & 31 & 21 & 9 \\
\hline LM & 2 & 1 & 1 & $9 * * *$ \\
\hline Graft & 9 & 8 & 14 & $3^{* * *}$ \\
\hline None/unknown & 40 & 8 & 10 & $34 * * *$ \\
\hline Mean LVEF \pm SD & $50 \pm 16$ & $55 \pm 14$ & $54 \pm 14$ & $53 \pm 14 * * *$ \\
\hline
\end{tabular}

DS = Diameter of stenosis; LAD = left artery, descending; $\mathrm{LCX}=$ left circumflex; $\mathrm{LM}=$ left main; $\mathrm{LVEF}=$ left ventricular ejection fraction; RCA = right coronary artery; other abbreviations, as defined in the text. Statistical tests (integral comparison of 4 groups): $* * \mathrm{p}<$ $0.01 ; * *$ p $<0.001$

CABG patients $(4.8 \%$ mortality) did not reach the required level of significance, which was prespecified as $\mathrm{p}<$ 0.0083

The 30-day MI rate according to the opinion of the CEC was lower among medically than non-medically treated patients, with the highest event rate observed in the CABG group (27.7\%); approximately half of the MIs in the PCI and CABG subgroups occurred within $48 \mathrm{~h}$ after the procedure. Differences in event rates as observed at 30 days were still present at the 6-month follow-up. Mortality was highest in the medically treated subgroup $(11.1 \%)$. Mortality rates were similar in the non-medical treatment subgroups (ranging from 5.5 to $6.5 \%$ ). MI rates as judged by the CEC were lowest in the medically treated patients $(20.8 \%)$ and highest in patients undergoing CABG (29.6\%). 


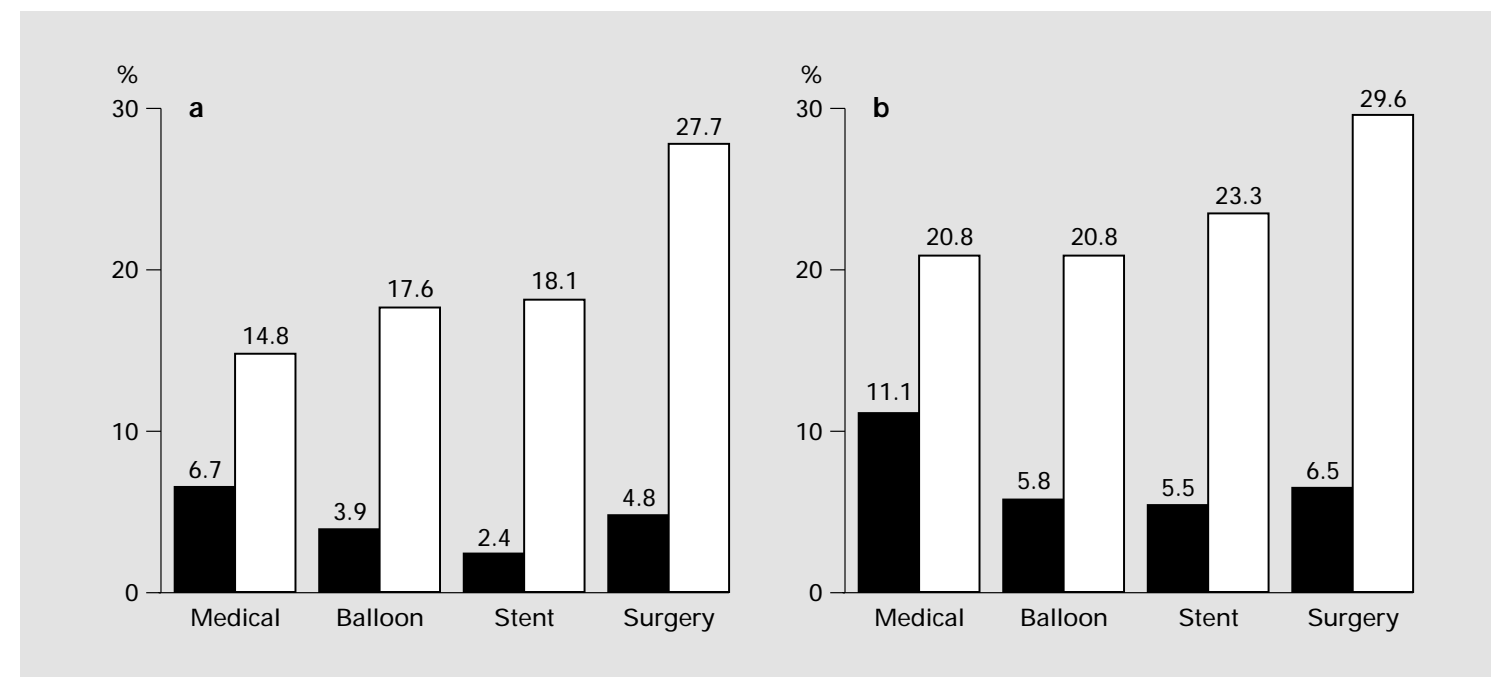

Fig. 2. 30-day (a) and 6-month (b) clinical outcome according to the treatment strategy applied. Black bars indicate mortality and white bars indicate MI adjudicated by the CEC. $p$ Values for the overall comparison between any of the treatment strategies applied (medical treatment, balloon, stent or surgery) and each clinical endpoint are as follows: a death: $\mathrm{p}=0.002$, MI: $\mathrm{p}=0.001$ both at 30 days and 6 months.

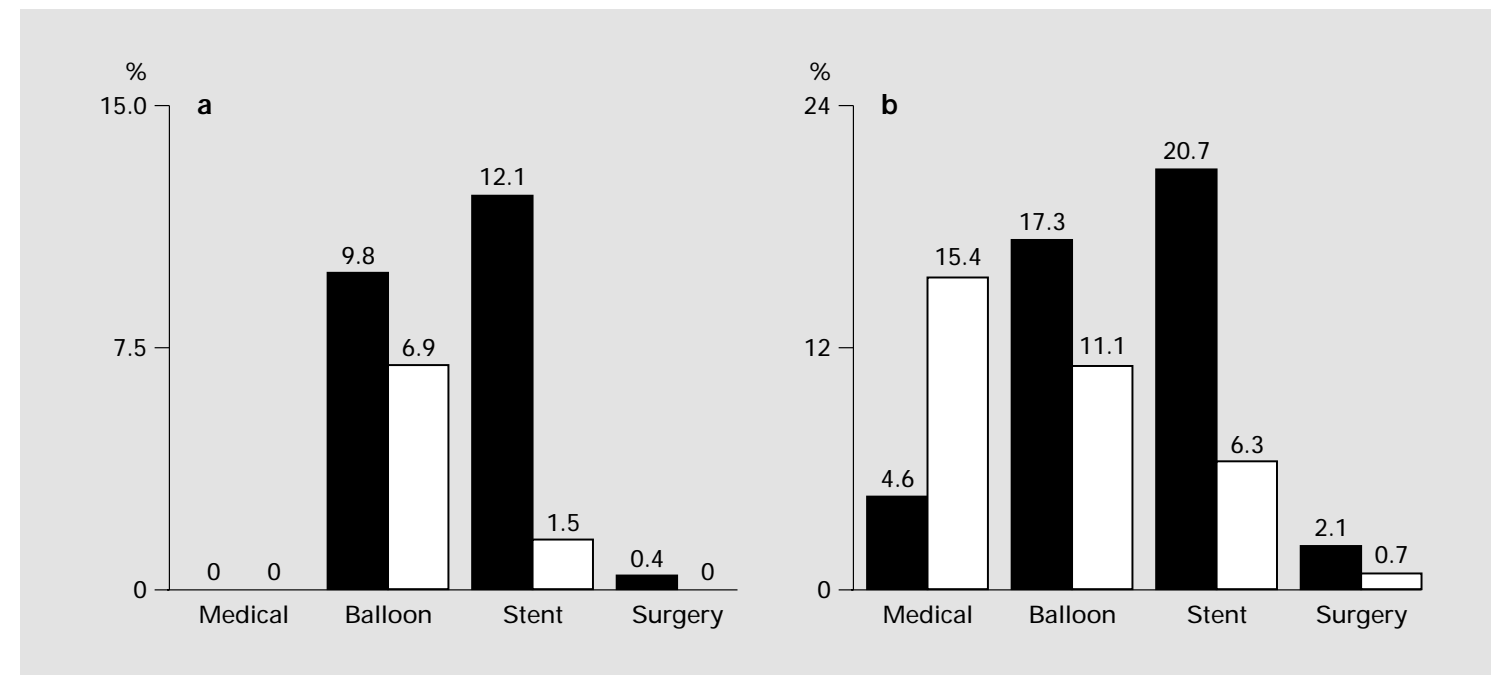

Fig. 3. 30-day (a) and 6-month (b) repeat revascularization procedures according to the treatment strategy applied. Black bars indicate PCI and white bars indicate CABG. $p$ Values for the overall comparison between any of the re-interventions and each group based on the treatment strategy applied initially (medical treatment, balloon, stent or surgery) are as follows: PCI, CABG: $\mathrm{p}<0.001$ both at 30 days and 6 months.

\section{Repeat Revascularization Procedures}

The rate of repeat revascularization at the 30-day and 6-month follow-up were significantly lower after CABG than after PCI (fig. 3). Patients undergoing stent implantation during the initial PCI had lower CABG rates at each of these 2 points in time when compared to non- stented patients. No apparent differences were observed in the rates of repeat interventions between stented and nonstented patients. A substantial number of medically treated patients still underwent a PCI (4.6\%) or CABG $(15.4 \%)$ procedure between 1 and 6 months after admission. 


\section{Discussion}

Patients who present with acute chest pain without persistent ST segment elevation represent a heterogeneous population, which spans from noncardiac chest pain (retrospectively diagnosed), to unstable angina and acute MI. The uncertainty in early clinical diagnosis forces clinicians to embark upon an empirical course of treatment, and this is the main reason why the clinical community still debates intensively regarding the optimal treatment strategy for patients with non-ST elevation acute coronary syndromes. Coronary angiography identifies patients with nonsignificant coronary stenoses and those with multivessel or left main disease. The former group has an excellent prognosis with a low risk of progression to MI or death, whereas the latter group, which is at an increased risk of progression to any of the aforementioned events, may derive a survival benefit from revascularization (either PCI or CABG) $[15,16]$. Patients who are not suitable candidates for standard revascularization or those who are at high risk of major perioperative complications due to comorbid conditions represent a distinct category in which medical treatment is preferred.

A major goal in PURSUIT was to understand the heterogeneity of the patient population and treatment strategies applied. The investigators therefore chose to embed the study of the effects of epifibatide in a real-life clinical setting including a broad spectrum of clinical practices, from rural hospitals to major tertiary referral centers around the world. To reflect actual clinical practice, no recommendations were made regarding the use and timing of coronary angiography, percutaneous coronary interventions or coronary bypass surgery, but all treatment decisions were left at the discretion of the team of treating physicians. Therefore, the results of the present descriptive analysis should be interpreted with this background in mind and viewed with the inherent limitations to subgroup analysis of randomized clinical trials [17].

Although not prospectively randomized to each of the treatment strategies compared, it is important to note that the medical therapy, early PCI and CABG ratio in these subgroups of 3,067 patients with an acute coronary syndrome and multivessel coronary artery disease was almost 1:1:1.

Indeed, important differences were observed in clinical characteristics and coronary anatomy between the distinct subgroups. Patients who did not undergo a coronary intervention within 30 days after enrolment, generally were in a less favorable clinical condition than patients undergoing early invasive treatment. The relatively high 30-day and 6-month mortality rate among medically treated patients is therefore not surprising and argues for the search of better treatment strategies in unstable patients with multivessel coronary artery disease that are not good candidates for revascularization procedures. Important determinants in the decision to refrain from invasive treatment in this patient population seem to be comorbid conditions, left ventricular dysfunction (medically treated patients more often had a history of CABG, heart failure, and a worse left ventricular function as compared to CABG patients) and the extent of coronary artery disease (medically treated patients more often had 3-vessel and left main disease as compared to PCI patients).

\section{Limitations}

This was a retrospective assessment of clinical, angiographic characteristics and clinical events in patients enrolled in a multicenter clinical trial and stratified according to the treatment strategy applied with a follow-up limited to 6 months, which can be considered as the main caveat of this study. We lack data on anginal status at baseline and 6 months; and on other predictors of adverse outcome such as completeness of revascularization; in both PCI and CABG patients. There were insufficient data on postprocedural cardiac enzymes as well. However, the present analysis reflected standard practice in a wide range of clinical settings, and contemporary treatment strategies for the management of patients with acute coronary syndromes and multivesel disease were used in this trial.

\section{Conclusions}

The observed major differences in clinical outcome are explained by an imbalance in baseline and angiographic characteristics between the groups of patients analyzed according to the treatment strategy applied. 


\section{References}

1 Hueb WA, Bellotti G, de Oliveira SA, Arie S, de Albuquerque CP, Jatene AD, Pileggi F: The Medicine, Angioplasty or Surgery Study (MASS): A prospective, randomized trial of medical therapy, balloon angioplasty or bypass surgery for single proximal left anterior descending artery stenoses. J Am Coll Cardiol 1995;26:1600-1605.

2 DiMarco J: Results from late-breaking clinical trials sessions at ACC 2001. J Am Coll Cardiol 2001;38:595-612.

3 Puel J, Karouny E, Marco F, Asoun B, Galinier M, Elbaz M, Alibelli MJ, Bounhoure JP: Angioplasty versus surgery in multivessel disease: Immediate results and in-hospital outcome in a randomized prospective study. Circulation 1992;86(suppl I):372.

4 Coronary angioplasty versus coronary artery bypass surgery: the Randomized Intervention Treatment of Angina (RITA) trial. Lancet 1993;341:573-580.

5 Rodriguez A, Boullon F, Perez-Balino N, Paviotti C, Liprandi MI, Palacios IF: Argentine randomized trial of percutaneous transluminal coronary angioplasty versus coronary artery bypass surgery in multivessel disease (ERACI): In-hospital results and 1-year follow-up. ERACI Group. J Am Coll Cardiol 1993;22:10601067.

6 Hamm CW, Reimers J, Ischinger T, Rupprecht HJ, Berger J, Bleifeld W: A randomized study of coronary angioplasty compared with bypass surgery in patients with symptomatic multivessel coronary disease. German Angioplasty Bypass Surgery Investigation (GABI). N Engl J Med 1994;331:1037-1043.
7 King SB 3rd, Lembo NJ, Weintraub WS, Kosinski AS, Barnhart HX, Kutner MH, Alazraki NP, Guyton RA, Zhao XQ: A randomized trial comparing coronary angioplasty with coronary bypass surgery. Emory Angioplasty versus Surgery Trial (EAST). N Engl J Med 1994;331: 1044-1050.

8 First-year results of CABRI (Coronary Angioplasty versus Bypass Revascularisation Investigation). CABRI Trial Participants. Lancet 1995;346:1179-1184.

9 Comparison of coronary bypass surgery with angioplasty in patients with multivessel disease. The Bypass Angioplasty Revascularization Investigation (BARI) Investigators. N Engl J Med 1996;335:217-225.

10 Rodriguez A, Bernardi V, Navia J, Baldi J, Grinfeld L, Martinez J, Vogel D, Grinfeld R, Delacasa A, Garrido M, Oliveri R, Mele E, Palacios I, O'Neill W: Argentine Randomized Study: Coronary Angioplasty with Stenting versus Coronary Bypass Surgery in patients with Multiple-Vessel Disease (ERACI II): 30day and one-year follow-up results. ERACI II Investigators. J Am Coll Cardiol 2001;37:5158.

11 Serruys PW, Unger F, Sousa JE, Jatene A, Bonnier HJ, Schonberger JP, Buller N, Bonser R, van den Brand MJ, van Herwerden LA, Morel MA, van Hout BA: Comparison of coronaryartery bypass surgery and stenting for the treatment of multivessel disease. N Engl J Med 2001;344:1117-1124.

12 Stables RH: Coronary artery bypass surgery versus percutaneous coronary intervention with stent implantation in patients with multivessel coronary artery disease (the Stent or Surgery trial): A randomized controlled trial. Lancet 2002;360:965-970.
13 Inhibition of platelet glycoprotein IIb/IIIa with eptifibatide in patients with acute coronary syndromes. The PURSUIT Trial Investigators. Platelet Glycoprotein IIb/IIIa in Unstable Angina: Receptor Suppression Using Integrilin Therapy. N Engl J Med 1998;339:436-443.

14 Bland JM, Altman DG: Multiple significance tests: the Bonferroni method. BMJ 1995;310: 170.

15 Bertrand ME, Simoons ML, Fox KA, Wallentin LC, Hamm CW, McFadden E, de Feyter PJ, Specchia G, Ruzyllo W: Management of acute coronary syndromes: Acute coronary syndromes without persistent ST segment elevation; recommendations of the Task Force of the European Society of Cardiology. Eur Heart J 2000;21:1406-1432.

16 Braunwald E, Antman EM, Beasley JW, Califf RM, Cheitlin MD, Hochman JS, Jones RH, Kereiakes D, Kupersmith J, Levin TN, Pepine CJ, Schaeffer JW, Smith EE, 3rd, Steward DE Theroux P, Gibbons RJ, Alpert JS, Eagle KA, Faxon DP, Fuster V, Gardner TJ, Gregoratos G, Russell RO, Smith SC, Jr: ACC/AHA guidelines for the management of patients with unstable angina and non-ST-segment elevation myocardial infarction: Executive summary and recommendations. A report of the American College of Cardiology/American Heart Association task force on practice guidelines (committee on the management of patients with unstable angina). Circulation 2000;102:11931209.

17 Yusuf S, Wittes J, Probstfield J, Tyroler HA: Analysis and interpretation of treatment effects in subgroups of patients in randomized clinical trials. JAMA 1991;266:93-98. 